\title{
Rumours Built on Quicksand: Evidence on the Nature and Impact of Message Board Postings in Modern Equity Markets
}

\author{
James Bowden \\ University of Dundee \\ Professor Bruce Burton \\ Professor David Power \\ j.bowden@dundee.ac.uk \\ University of Dundee \\ University of Dundee \\ b.m.burton@dundee.ac.uk \\ d.m.power@dundee.ac.uk
}

This is an Accepted Manuscript of an article published by Taylor \& Francis in European Journal of Finance on 14 February 2017, available online: http://www.tandfonline.com/doi/ full/10.1080/1351847X.2017.1288647 


\title{
Rumours Built on Quicksand: Evidence on the Nature and Impact of Message Board Postings in Modern Equity Markets
}

\begin{abstract}
It is argued that internet-based short-sellers take advantage of asymmetric information, publishing research online which often values shares in a target company at a large discount to their current price. The increasing popularity of online dissemination of information, coupled with evidence that individuals are prone to behave in a herd-like fashion suggests the potential for significant volatility in the share price of a company. In this paper, a dataset of 12,616 financial message board postings is employed to examine patterns in online activity following the publication of a research note targeting a specific firm by an internetbased short seller. Identifiable trends in investor behaviour, indicative of community contagion, are shown with group sentiment shifting over time. The findings have implications for regulators' attempts to adapt to an online environment in which information - and misinformation - can be rapidly incorporated into share prices.
\end{abstract}

Keywords: internet-based short seller, financial regulation, lower-tier financial markets, market efficiency 


\section{$1 \quad$ INTRODUCTION}

A new form of financial intermediary, the internet-based short seller, has grown in prominence over recent years. For example, it has been argued that asymmetric information and a lack of due diligence associated with Chinese companies listing on stock exchanges in the United States (Chen, 2015) allowed short-sellers to effectively “wipe” \$21 billion of market value from such firms between 2010 and 2011 (Bases et al., 2011). In Europe, second-tier markets have received similar criticism following recent attacks by internet-based short-sellers on listed companies. The bankruptcy of the telecoms provider Let's Gowex SA, for example, previously listed on the Spanish Alternative Investments Market, followed the publication of a research report by an internet-based short seller valuing the company at 0p (Martinez, 2015).

Second-tier markets have thrived since their inception, serving as a platform for smaller, high-growth firms to access capital while benefitting from a lower cost of listing in comparison to the more established main markets (Mendoza, 2008). However, such benefits may come at the cost of comparatively lower levels of regulatory scrutiny, presenting an increased risk of information asymmetry and potential fraud (Martinez, 2015). Companies characterised by complex business models, aggressive accounting choices and a listing on lower-tier markets are particularly at risk of attack by internet-based short-sellers ${ }^{1}$. Such "shortseller” investors within the markets have long been the subject of academic study (see, e.g. Holderness and Sheehan, 1985) and wider public discourse. However, the increasing frequency of short-seller "attacks" in particular are leading to a heightened level of concern among listed companies and those trading in their equity. ${ }^{2}$

\footnotetext{
${ }^{1}$ In some instances, such as that of Gowex, short-seller claims regarding a target company can be ultimately supported by later events, which has led to claims by notorious short-seller Daniel Yu that these incidents "validate the critical role that short selling plays in the financial markets [and] regulators' initial response should not be to shoot the messenger” (Kelley, 2014).

${ }^{2}$ One hundred and forty-three companies globally were subject to short-seller attacks in 2015, compared to one hundred and five in 2014, with the share price of most of those targeted falling by over $50 \%$ following the publication of a report by an activist short-seller (Activist Insight, 2016). By comparison, studies of the effects of
} 
Instances of false statements disseminated via social media platforms and message board postings continue to feature in mainstream media, ${ }^{3}$ complicating attempts to determine the accuracy of short-seller claims. Such activity has been evident since the emergence of online financial communities, with participants advised to follow the "caveat emptor" principle (Chambers, 2006: 47). It can therefore be difficult for online community members to ascertain the authenticity of information published online and distinguish facts from speculation. The manner in which investors respond to online short-seller research reports is therefore a phenomenon in need of detailed contemporary scrutiny. ${ }^{4}$

One recent instance of internet-based short-seller activism and subsequent investor behaviour concerns a research note published by internet-based short seller Gotham City Research attacking Quindell PLC, an information technology outsourcing company listed on the Alternative Investments Market (AIM) submarket of the London Stock Exchange. Following Quindell PLC chairman Robert Terry's resignation on $18^{\text {th }}$ November 2014, popular free London circular City A.M. declared that Gotham City Research had "got its man" (Gordon, 2014a). A 74-page research dossier published online by a mysterious short-seller, Gotham City Research LLC (GCR) was credited as marking the "beginning of the end" for Mr Terry (Gordon, 2014b). A ‘tweet' by GCR on $22^{\text {nd }}$ April 2014 via the social media platform 'Twitter', linking to this research dossier referred to Quindell PLC as a "country club built on quicksand”;

\footnotetext{
investing by "long-buyer" activists yield less dramatic results. For example, Becht et al. (2010: 3126) report that "well-focused" activist engagements can result in "substantial public returns". However, the magnitude of shortterm excess returns for long-term activist investors observed by Ryan (2006) are considerably smaller relative to the excess returns documented around short-selling campaigns.

${ }^{3}$ In a recent example, a stock manipulation scheme of falsely defaming two United States' companies via microblogging website Twitter and originating in Scotland was recently uncovered, resulting in federal indictment (Williams, 2015).

${ }^{4}$ It would be insightful to compare the market reaction to negative and positive notes from research firms' shortselling dossiers. However, short selling activists typically offer only "strong sell" recommendations, valuing the shares of target firms at a considerable discount to their current trading price. Therefore, such a comparison was not possible.
} 
this was seen as the primary contributor to a $52 \%$ fall in the company's share price within 40 minutes of the comment's publication (Ficenec and Martin, 2014).

The share price of Quindell PLC has not since recovered; trading in the firm's shares was temporarily suspended in June 2015, during which time the company was investigated by the Financial Conduct Authority. On resumption of trading some six weeks later, the firm's shares were valued at 93.5p, a drop of $86 \%$ from the record high of 656.25p reached just days prior to publication of GCR's research note. This is perhaps initially surprising, given that GCR disclosed within its note that readers should "assume, as of the publication date of this report, that [GCR] stands to profit in the event the issuer’s stock declines” (Gotham City Research, 2014a). ${ }^{5}$

This article highlights the challenges faced by financial regulators in attempting to remain relevant in an era where speed, high levels of interactivity and low communication cost amplify the effects of social contagion and behavioural biases (Russ, 2007). In an age where technological advancements allow for the almost instantaneous broadcast of information to a vast global audience, it is possible that the effects of such information can be incorporated into share prices almost immediately, before more sophisticated, knowledgeable investors can arbitrage away any mispricing. The existence of online communities, such as message boards, provides a useful "real time window" through which researchers can observe interactions among participants (Das et al., 2005) and comment on existing theories regarding a herding tendency in equity transactions. Thus, it becomes possible to analyse conversations among investors through the lenses of both standard and behavioural finance theory, and seek to measure the authenticity of long-standing social phenomena such as the "madness of crowds"

\footnotetext{
${ }^{5}$ At the end of September 2016, 144 instances of short positions in securities listed on the London Stock Exchange, representing more than $0.5 \%$ of outstanding shares in the firms concerned were disclosed by fund managers (Castellain Capital, 2016a).
} 
(Mackay, 1841), within communities often presented with "high strength, low weight” news and opinion (Griffin and Tversky, 1992; Barberis et al., 1998). The implications of this dynamic situation should be of concern for regulators, with adverse impacts on the share prices of target companies within minutes of accusatory research being published online.

This paper reports the results of two distinct forms of analysis. First, using a model of abnormal returns over time similar to that adopted by Bruner (1999), we evaluate the reaction of the broader market to key events around the time of the publication of GCR's short sale research note. We then explore the reaction to the dossier within a dedicated online financial community, the Advanced Financial Network (ADVFN). Specifically, through analysis of 12,616 individual message board postings referring to Quindell PLC, we investigate the reaction of the virtual community, utilising both daily and intraday sentiment to identify collective emotion prior to, and immediately following the event. The remainder of this paper is structured as follows. The next section provides an overview of the background surrounding the publication of GCR's research note on Quindell PLC, before Section 3 discusses the relevant literature. Methods utilised by the researchers are then introduced with a preliminary analysis of the data in Section 4. A summary of the findings is provided in Section 5 before Section 6 offers concluding remarks, setting out the potential implications of the evidence for capital market regulators. 


\section{RELATED LITERATURE}

Baker (1984) defines financial markets as “social structures”, a point of view shared by Shiller (1984), who refers to investing as a "social activity" due to the amount of leisure time spent by investors either reading about or discussing investments, or 'gossiping' about other investors and their relative (lack of) success. The social aspect of investing is perhaps no better evidenced than through the activities of online communities, such as social media sites and online message boards; academics from both the social sciences and the computational linguistics field have set out to identify the impact of message boards on measures of corporate performance such as market returns.

Zhang (2014) estimates that approximately 50 papers on this subject have appeared since the pioneering work of Wysocki (1998), in which the author rejected the notion that all online interactions could be dismissed as "noise", with the volume of overnight postings in fact being strongly associated with a (modest) increase in abnormal returns at the start of the next trading day. However, no clear consensus exists with several studies identifying strong relationships between message board postings of online "crowds" and market activity, and others finding no such evidence. Tumarkin and Whitelaw (2001) for example, find no evidence that information with respect to subsequent returns is contained within the 'user ratings' of an online message board community.

An instrumental study by Bikhchandi et al. (1992) proposed that investors engaged in observational learning in an attempt to deal with the "informational cascade" of abnormally high numbers of 'buy’ or 'sell’ signals. Devenow and Welch (1996) argued that such behaviour could be construed as reflective of "rational herding" where actions, rather than details about private information, were publicly visible. However, Avery and Zemsky (1998) suggested that in a market-trading setting where a price is not fixed, informational cascades cannot take place. 
In these authors' model, agents would instead find it optimal to trade on the difference between their own information and publicly available news. It has also been suggested that passively mimicking the choices of other investors constitutes irrational herding, which could explain the presence of asset bubbles such as that which occurred during the "dot-com boom" (Simonsohn and Ariely, 2008).

Clear herding patterns, associated with shares of companies that are heavily discussed within virtual communities, have been identified recently (Zhang, 2014). Occasions of share price manipulation through the posting of false information on financial message boards, and the collective action that follows, were especially well-documented during the dot-com era, at which time financial message boards were portrayed as a "virtual Wild West...with posters gleefully shooting down stocks” (Foust, 2001). Instances of message board postings by "pumpers and dumpers" rapidly grew in prominence, with these postings being disseminated among the online crowd almost instantly. Little doubt exists that that the arrival and extraordinary growth of the internet has profoundly changed the dynamics of financial markets (Fan et al., 2000), altering the manner in which information is delivered to investors, and the ways in which investors can act upon news (Barber and Odean, 2001). Through online news and opinion platforms, investors possess timely, low cost access to a wide range of information and speculation. ${ }^{6}$ However, a geometric increase in the quantity of digital information available over time, although particularly useful for academic purposes (Nardo et al., 2015), introduces the potential for individual information overload, a point at which all communication inputs cannot be processed and utilised, leading to systemic breakdown (Jones et al., 2004). In such cases the introduction of cognitive biases leads to “non-optimal decision making” and evidence

\footnotetext{
${ }^{6}$ Further, technology allows for fast dissemination of material published with the intent of affecting investors' perceptions of stocks (Leinweber and Madhaven, 2001)
} 
of subsequent mental shortcuts, such as the herding phenomenon, can occur (Allen and Wilson, $2003)^{7}$.

Barber and Odean (2001) have expressed concern that the vast quantity of online data now available makes it considerably easier for investors to confirm their own beliefs, potentially leading to overconfidence in their own opinions. The authors further suggest that securities gain the attention of investors' through coverage by media outlets, or abnormal trading activity, potentially amplifying the effects of online short-seller activity; this outcome is particularly likely in an era where social media posts can go "viral”, achieving a global audience within seconds. Ultimately, as the authors warn, “...all that glitters is not gold” (Barber and Odean, 2008: 804).

Interactions within online communities can be explained from a psychological, as well as an economic perspective (Chen et al., 2008). Individuals are more prone to interact with those that share similar opinions in order to confirm their own beliefs (Gilovich, 1991). Das et al. (2003) identify the sharing of ideas with like-minded people as a primary motivation for some investors' participation in stock message boards. Further, McPherson et al. (2001) suggest that individuals tend to act in a homophilous manner, i.e. they interact with others sharing similar backgrounds or beliefs. According to Shefrin (2000, p63), investors “focus on evidence which confirms their views but overlook evidence that is contradictory”.

Conventional understandings of trust imply that even if an opinion expressed online is consistent with our own perceptions, it should be taken with a grain, if not a "rock of salt" (Dewally, 2003). In an anonymous online environment in which the infamous New Yorker cartoon declared “nobody knows you're a dog” (Steiner, 1993) it is inevitably difficult to assess the credibility of information thereby obtained (Morris et al., 2012). Previous research suggests

\footnotetext{
${ }^{7}$ Numerous publications argue that online behaviour is becoming increasingly homophilous, herd-like and potentially even more “stupid” (Bentley et al., 2014).
} 
that online users "lack the clues that they have in the real world to assess the credibility of the information to which they are exposed” (Mendoza et al., 2010: 675). More recent evidence suggests that users are in fact poor judges of the truthfulness of online information based on content alone, and are instead influenced by heuristics such as user name (Morris et al., 2012). In a financial context, relying on heuristics to draw inferences from available information is indicative of human (Shefrin, 2000; Statman, 1999), and not rational behaviour ${ }^{8}$. Chen (2013) argues that message board participants recognise each other's usernames over time, and when reading and responding to messages from other online participants that they know via their virtual domain place particular trust on the information concerned. However, Resnick et al. (2000) describe online anonymity as "double-edged"; while on the one hand it limits the depth of online interactions, on the other it effectively 'level[s] the playing field' - the opinions of an individual investor who trades in his spare time can carry just as much weight as a full-time analyst at a large investment bank, as no participants are any the wiser about who they are interacting with.

A framework developed by Griffin and Tversky (1992) allows the beliefs of individual investors to be updated based on the 'strength' and 'weight' of new evidence presented to them. Taking a recommendation letter as an example, the authors define 'strength' as the positivity and warmth of the content, and 'weight' as the credibility and stature of the person making the recommendation. Their research finds that people focus too much on the 'strength' of a letter, and attach insufficient importance to its 'weight'. In the context of financial markets, Barberis et al. (1998) build on this study, finding that prices underreact to low-strength, high-weight events such as earnings announcements. Within the online environment, however, the weight of an announcement may be low since the individual behind the disclosure may not be known.

\footnotetext{
${ }^{8}$ Studies testing for stock message board and share price relationships suggest noise traders can affect security pricing in an environment in which information can be quickly shared and disseminated online (Wysocki, 1998).
} 
The instance of Quindell PLC and GCR is intriguing, as it suggests that message boards and other social media platforms may be employed by internet based short-sellers to exploit behavioural biases and induce a herd mentality within both the online "crowd" and the wider investment community. There are therefore two primary questions we must ask. Firstly, did the GCR dossier trigger the formation of a "crowd" within the virtual domain? Secondly, was there a correlation between this crowd sentiment and abnormal returns?

\section{METHODS AND SUMMARY DATA}

\subsection{Selection of the Dataset}

Following an increase in successful short-seller attacks in recent years, data provider Activist Insight (2016: 26) declared that it was currently “difficult to be an activist investor, [but] a hoot to be in the activist short-selling game.” The impact of short-selling research firms increased markedly in 2013 and $2014,{ }^{9}$ with the largest average return in a single campaign during this period achieved by GCR. ${ }^{10}$ Furthermore, trading activity in firms targeted by GCR increased by $2,750 \%$ on the day on which a report was published relative to the previous trading day; it is therefore apparent that GCR has a substantial degree of influence over investor behaviour in the companies that they target.

The present study focusses on message board postings and pricing data surrounding GCR's research note regarding Quindell PLC. ${ }^{11}$ The sample of message board postings is restricted to this event, because of the extreme nature of the shorting which occurred, ${ }^{12}$ the

\footnotetext{
${ }^{9}$ During a 20-month period between January 2013 and August 2014, companies targeted by 15 of 22 "notorious" short-sellers generated negative returns (Activist Shorts Research, 2014)

${ }^{10}$ GCR has launched seven campaigns against firms listed in the USA, Spain and the UK since its inception, with the average recorded price drop of a target company on the day that one of its reports was published equalling $37.13 \%$.

${ }^{11}$ Background information regarding the case is provided in Appendix 1

${ }^{12}$ Described in a Financial Times editorial as "one of the highest profile shorting campaigns in UK history" (Johnson, 2014)
} 
second-tier market status of the target company, and the sector in which the target firm operates. ${ }^{13}$ The case has an additional element of intrigue given Quindell's decision to list on AIM through the "backdoor" process of a reverse merger, an increasingly popular method of listing by both foreign and high-tech firms allowing companies to "focus more on their business, and less on compliance” (Vermeulen, 2015: 422). Adjei et al. (2008) find that 1.4\% of private firms using reverse mergers as a listing mechanism do not meet any listing requirements, and $42 \%$ are delisted within three years of being admitted to an exchange. As such, these firms are often targeted by internet-based short-sellers. ${ }^{14,15}$

The 74-page document produced by GCR, and which provides the dataset for this study, contains extensive detail, including financial ratio analysis, information about inconsistencies in the firm's revenue recognition decisions and personal as well as professional connections between Quindell PLC executives, acquired firms and its primary customers. ${ }^{16}$

\subsection{Share Returns and Trading Volume Data}

Our analysis employs two separate datasets of share price information relating to Quindell PLC. The first contains end of day price and volume data between $4^{\text {th }}$ April 2014 and $22^{\text {nd }}$ May 2014. After excluding public holidays and weekends, this provides a 31 day trading period running from 10 trading days prior to the publication date of GCR's tweet to 20 trading days thereafter. Such a relatively long observation period is used to identify trading activity and

\footnotetext{
${ }^{13}$ Firms within the technology sector were subject to more short-seller notes than any other sector in 2015 (Activist Insight, 2016). Indeed, of the seven campaigns that GCR has launched, five targeted technology firms.

${ }^{14}$ Perhaps the highest profile instance of such is provided by the case of Sino-Forest Corp., a Chinese firm listing on the Toronto Stock Exchange through the process of a reverse merger. The company subsequently attained a market valuation of $\$ 6 \mathrm{bn}$, before being subject to a scathing online research note by short seller Muddy Waters $L L C$. The firm would later file for bankruptcy.

${ }^{15}$ Liu et al. (2015), for example, identify 62 Chinese companies listing on foreign exchanges which were subsequently attacked by short-sellers between 2010 and 2011, resulting in a reduction of almost $50 \%$ in the equity value of the targeted firm.

${ }^{16}$ The length of GCR's initial research notes historically average 60.43 pages, consistent with other notorious short sellers, such as Muddy Waters LLC (58.23 pages).
} 
posting sentiment levels prior to the short-seller research note and assist in identifying trends, both short-term and long-term, following the event. We label the day on which the GCR tweet occurred, $22^{\text {nd }}$ April 2014, as day $d$. All other observation days are denoted by their proximity to day $d$, from $d-10$ to $d+20$.

The second dataset contains intraday price and volume data for Quindell PLC at fiveminute intervals from $22^{\text {nd }}$ April $2014(d)$ to $25^{\text {th }}$ April $2014(d+3)$. A similar methodology is employed to that utilised by Bruner (1999) in his study of abnormal returns surrounding key events ${ }^{17}$ around the failed merger of Volvo and Renault ${ }^{18}$. Market-adjusted returns for each day and for each five-minute interval are calculated as;

$$
A R_{t}^{i}=\left(\frac{P_{t}^{i}+D_{t}^{i}}{P_{t-1}^{i}+D_{t-1}^{i}}\right)-\left(\frac{P_{t}^{m}}{P_{t-1}^{m}}\right)
$$

where: $P_{t}^{i}=$ the closing price of Quindell PLC Shares at interval $t$;

$D_{t}^{i}=$ any dividend distributions to Quindell PLC shareholders effective at interval $t$; $P_{t}^{m}=$ the total return index value of the FTSE Small Cap index, a market capitalisationweighted index of smaller-capitalisation companies listed on the main market of the London Stock Exchange, ${ }^{19}$ at interval $t$.

Abnormal returns are computed in single day periods over the 31-day observation window for daily data, and in 5-minute intervals between 12.30pm and 2.00pm on day $d$ for intraday data. Abnormal trading volume is measured by deducting the percentage change in the number of

\footnotetext{
${ }^{17}$ Dates and timestamps of announcements regarding Quindell PLC were extracted from the London Stock Exchange website, with further cross-referencing against a timeline of Quindell PLC-specific events compiled by the Financial Times online.

${ }^{18}$ Incorporation of costs such as the bid-ask spread in abnormal return calculations would have provided an interesting comparison to the model utilised in Bruner's (1999) study. An attempt was therefore made to obtain information relating to such costs over five-minute intervals during the observation window, but this was not possible.

${ }^{19}$ The analysis was also repeated with the FTSE All Share and the FTSE AIM All Share indices, and the results were largely similar.
} 
shares traded for constituents of the FTSE Small Capitalisation Index, from the percentage change in daily trade volume for Quindell PLC shares over the two time intervals; ${ }^{20}$

$$
A T V_{t}^{i}=\left(\frac{T V_{t}^{i}}{T V_{t-1}^{i}}\right)-\left(\frac{T V_{t}^{m}}{T V_{t-1}^{m}}\right)
$$

where: $T V_{t}^{i}=$ the trading volume of Quindell PLC Shares during interval $t$;

$T V_{t}^{m}=$ the trading volume of constituents within the FTSE Small Cap index during interval $t$

Price and trade volume data for Quindell PLC shares are presented in Figure 1; preliminary analysis of the two datasets indicates that the GCR tweet had an impact on both. For example, Panel A illustrates that the reaction of the investment community to the news of GCR's research dossier was negative, with a one day return of $-39.10 \%$. The largest daily trade volume observed - by some distance - also coincides with day $d$, when 32.3 million shares in Quindell PLC were traded. ${ }^{21}$ Panel B presents five-minute share price and trade volume data for Quindell PLC on day $d$, and further illustrates the magnitude of the immediate reaction to GCR's research note tweet at 1.02pm.

A negative absolute return of $49.66 \%$, reflecting a fall in the price of Quindell PLC shares from $551.25 \mathrm{p}$ to $277.50 \mathrm{p}$, occurred during the five-minute period between $1.00 \mathrm{pm}$ and $1.45 \mathrm{pm}$ on event day $d$, equating to almost $£ 1$ bn being wiped off the company’s market value. ${ }^{22}$ Conversely, the FTSE Small Cap Index generated a positive absolute return of $0.003 \%$,

\footnotetext{
${ }^{20}$ As per Bruner's (1999) study, the significance of accumulated abnormal returns and trading volumes is analysed via a t-value, computed by dividing accumulated abnormal returns by estimated standard deviation, $t=A R_{t} / S E_{t}$, where the estimated standard deviation of abnormal returns is calculated using data from the 365-day period immediately prior to the observation window for daily returns, and intraday data between 1st and 16th April 2016 for five-minute intervals.

${ }^{21}$ To put the scale of this observed trading volume into perspective, the number of Quindell PLC shares traded on day $d$ represents $39.04 \%$ of the combined trade volume for all companies included in the FTSE Small Cap Index, and $541 \%$ of the average trading volume in Quindell PLC shares observed between $d-10$ and $d-1$ inclusive.

${ }^{22}$ The abnormal returns model utilised by Bruner (1999) is more suited to highly liquid stocks; given the consistently high abnormal trade volume in Quindell PLC shares on or around the publication of GCR's note, it was considered appropriate in this instance.
} 
suggesting that no broader market shocks coincided with this rapid fall in Quindell PLC's share price. ${ }^{23}$ Trading in Quindell PLC’s shares increased, with 4.05 million shares being bought and sold in the five-minute period following GCR's initial tweet. Trading volume exceeded one million during three separate five-minute periods within the first hour following of GCR's tweet, levels of transactions not recorded at all in the 10 days preceding day $d$; trade volume prior to noon on the event day averaged only 22,903 shares per five-minute period.

\subsection{Message Board Postings}

Although a large number of message boards exist within the virtual domain, covering a wide array of global exchanges and markets, the Advanced Financial Network (ADVFN) was selected for analysis in the current paper because it focusses on securities listed on the London Stock Exchange and its submarkets. ${ }^{24}$ The ADVFN platform has approximately 800,000 users within the UK and has hosted over 17 million messages since its inception in 1999. ${ }^{25,26}$

In conventional message board terminology, a message thread refers to an online dialogue and usually contains numerous postings relevant to the thread topic. A thread creator initiates conversations, specifying the thread's topic at the outset. The focus may be specific to a recent event (for example a recent earnings announcement, a major new contract or a broker’s report), or it may relate instead to a broader discussion of a company’s activities. It may also take the form of a generic trading thread, or involve a discussion regarding other topics entirely.

\footnotetext{
${ }^{23}$ Thirty-two company-specific news updates were recorded by the Regulatory News Services (RNS) on $22^{\text {nd }}$ April 2014 prior to 2pm, of which none held obvious implications for the operations of Quindell PLC. Eleven of the updates concerned companies within the technology sector, of which three related to a change within the shareholdings of a company; five concerned director shareholding disclosures and the remainder concerned preliminary results and announcements of industry awards (Investegate, 2016).

${ }^{24}$ Of all messages observed on the ADVFN message boards between $1^{\text {st }}$ July 2015 and $31^{\text {st }}$ December 2015, 46.04\% concerned AIM-listed securities, 13.14\% related to the UK Main Market, 6.56\% the International Main Market and the remaining 34.26\% either focussed on securities not listed on the London Stock Exchange, or were "off-topic" in their nature.

${ }^{25}$ For comparison, the Motley Fool UK message board site, also one of the most frequented online communities specialising in LSE-listed equities, has attracted 7.4 million postings since its inception.

${ }^{26}$ Further, as Quindell PLC is an AIM-listed company that, until 2014, had been highly-tipped for a main market listing and inclusion within the FTSE 250 (Mance et al., 2014), we considered ADVFN to be the most suitable and active message board platform to use for our analysis.
} 
Users can then reply to the thread creator's initial message, and the discussion thus develops within the thread over time. Message board threads in which a participant has posted a message most recently will appear at the top of the list of threads. In doing so, an inactive thread falls down the message board list as new threads are created. Thus, old threads essentially become dormant.

Using a web scraper constructed with the Python programming language, we extracted and analysed 12,616 ADVFN message board postings concerning Quindell PLC, during and following the publication of GCR's research dossier. The message board postings span the period from April $3^{\text {rd }}$ to May 22 $2^{\text {nd }} 2014$, during which time 855 unique users posted Quindell PLC-specific messages. These users varied greatly in terms of their level of activity. ${ }^{27}$ Posting activity during the observation period is presented in Figure 2. Panel A suggests that daily frequency varied greatly during the observation period, further evidenced by a standard deviation of 304.9 posts per day. Posting volume both on day $d(1,192)$ and average daily posting volume between $d+1$ and $d+10$ (477.8) were predictably greater than the average number of daily posts beforehand (186.9). The highest level of posting occurred on day $d+3$ $(1,254)$ with the lowest observed on day $d-5$ (115). Panel B illustrates the cumulative posting volume throughout the observation period within five-minute time intervals. As expected, posters were more active during trading hours (8am - 4.30pm GMT), with the highest level of volume occurring shortly after the open and immediately following the close of the market. Minimal post volume was observed between midnight and 7am GMT, suggesting that a majority of posters are based within the UK and the surrounding region.

Abnormal posting volume is measured by comparing actual volume over interval $t$ with the average volume for a previous period immediately prior to the observation window; for the

\footnotetext{
27 The most active user contributed 683 messages during the 31-day window. 287 users however only posted once during the entire period. 92 posters contributed, on average, at least one message per day.
} 
daily data, the previous period spanned the 31 days prior to day $d-10$ while for the five-minute data, the previous period related to intraday posting volume data between April 1st and April 16th 2016.

\subsection{Message Board Sentiment}

A Naïve Bayesian probabilistic classifier is employed using the Natural Language Toolkit platform available through the Python programming language. Bayesian classifiers, such as the Naïve model, incorporate independence assumptions (Zhang, 2014). However, this "bag of words” approach has proven to be particularly effective in previous studies (e.g. Das and Chen, 2007; Antweiler and Frank, 2004). ${ }^{28}$ Using Bayes' rule, the probability that a new message board posting, $d_{m}$ belongs to a sentiment category, $\theta_{j}$, is given as:

$$
p\left(\theta_{j} \mid d_{m}\right)=\frac{p\left(d_{m} \mid \theta_{j}\right) p\left(\theta_{j}\right)}{p\left(d_{m}\right)}
$$

The classifier is first trained using a selection of 2,250 Quindell PLC-specific message board postings obtained from ADVFN in the calendar month prior to the observation window (March $1^{\text {st }}$ to March $30^{\text {th }}, 2014$ ) and the three-month period thereafter (June $12^{\text {th }} 2014$ - September $11^{\text {th }}$ 2014). When considering the size of the training dataset we followed Zhang et al. (2010), who demonstrated that ineffective text classifiers primarily result from unbalanced information data. An equal number of 375 training posts is therefore assigned to each of six sentiment categories and incorporated into the training set; Strong Buy (+2), Buy (+1), Hold (0), Sell (1), Strong Sell (-2) and Short Sell (-3), ${ }^{29}$ to avoid potentially skewing the model. ${ }^{30}$ These

\footnotetext{
${ }^{28}$ Along with Support Vector Machine (SVM) text classifiers, Bayesian models have been adopted by a large number of researchers in the field of virtual communities (Schumaker and Chen, 2009; Das and Chen, 2007; Gu et al., 2008; Antweiler and Frank, 2004)

${ }^{29}$ This coding approach was first implemented by Tumarkin and Whitelaw (2001) and has been adopted by numerous studies since.

${ }^{30}$ This procedure also controls for a potential overfitting of data, and is consistent with training set sizes recommended by Das and Chen (2007)
} 
sentiment scores for each posting are aggregated across all postings in a time period, $t$, and an overall sentiment score $\left(S_{i, t}\right)$ is determined. An abnormal sentiment score is then calculated by deducting an average sentiment score value over a prior period (between $t-k$ and $t-l$ ) from the sentiment score for period $t$; for the daily data, the prior period included the 31-day period ending on day $d-11$ while for the intraday data, the prior period related to intraday sentiment data between April $1^{\text {st }}$ and April 16 ${ }^{\text {th }} 2016$ :

$$
A S=S_{i, t}-\bar{S}_{t-k, t-l}
$$

The training data is assigned a score based on our own manual evaluation of the sentiment expressed within training posts. Zhang (2014) argues that a sentiment index should correctly reflect the emotion expressed by the poster and not the second-hand emotion(s) assigned by researchers. Manually assigned sentiment may leave data susceptible to subjective bias. Indeed, Zhang et al. (2010) assert that only self-disclosed sentiment messages should be incorporated into training data, eliminating human interpretation bias. However, unlike many popular online message boards, the ADVFN community does not offer a self-disclosed sentiment feature to participants. Messages simply contain the text of the post's author, and therefore it is impossible to utilise self-disclosed sentiment in the current study. Instead, an assessment of sentiment by the researchers is used in the current investigation. Once trained, the accuracy of the classifier model is tested. Our trained Naïve Bayes classifier achieves an overall accuracy score of 70.1\%. ${ }^{31}$ Das and Chen (2007:5) achieve a similar degree of accuracy in their study, noting that "high ambiguity makes higher levels of accuracy difficult to achieve”.

In addition to the abnormal sentiment score, we also construct two additional measures of message board sentiment during the observed period and test each for an association with

\footnotetext{
${ }^{31}$ The total of $70.1 \%$ comprises $11.1 \%$ (percent of testing dataset classified as "Strong Buy" by the authors and our model) + 10.4\% (correctly assigned by the model as "Buy") + 15.2\% ("Hold”) + 10.1\% ("Sell”) + 10.7\% (“Strong Sell”) + 12.6\% (“Short Sell”).
} 
abnormal returns over daily and five-minute intervals. Firstly, in accordance with Antweiler and Frank (2004), message classifications are grouped into "Buy", "Hold" and "Sell” categories. "Buy” postings are assigned a score of 1 , "Hold” postings are assigned a zero score, and "Sell" postings are given a value of -1 . These values are then aggregated to obtain a bullish signal, $B_{t}$, for each time interval, and a "Bullishness Index" is created thus:

$$
B_{t} \equiv \frac{M_{t}^{B U Y}-M_{t}^{S E L L}}{M_{t}^{B U Y}+M_{t}^{S E L L}}
$$

where: $M_{t}^{B U Y}=$ the number of message board postings assigned with a sentiment score of 1 or higher during interval $t$;

$M_{t}^{S E L L}=$ the number of message board postings assigned with a sentiment score of -1 or lower during interval $t$

Equation [5] is independent of the overall number of messages and therefore provides a useful tool for comparison over time. However, we also utilise a "Modified Bullishness" ratio suggested by Cook et al. (2014) which accounts for messages assigned a "Hold” value of zero:

$$
M B_{t}=\frac{M_{t}^{B U Y}-M_{t}^{S E L L}}{M_{t}^{B U Y}+M_{t}^{S E L L}+M_{t}^{H O L D}}
$$

where: $M_{t}^{H O L D}=$ the number of message board postings assigned with a sentiment score of 0 during interval $t$.

These three sentiment measures are used in this study as although similar, they provide different perspectives on sentiment and thus allow for robust investigation of relationships between abnormal returns and community sentiment. Our measures of abnormal returns, trade volume, posting volume and community sentiment, measured over both daily and five-minute intervals, are employed to investigate the behaviour of both the online and broader investment communities throughout the observation period, and to identify the presence of social 
contagion and herding. Further, we are able to address whether this behaviour is consistent with our understanding of "rational” market participants.

\section{FINDINGS}

The information that GCR included in their dossier on Quindell PLC was publicly available via various online portals and company filings, and so in an efficient market this information should have already been incorporated into the value of the firm's shares. Further, at 74 pages, investors might reasonably be expected to take time to digest such material before acting upon it. Our observations are not consistent with this expectation; instead, we find a significant reduction in online community sentiment levels (change in abnormal sentiment on day $d=-0.67$, t-value $=-2.48)$ and negative abnormal returns $(-39.46 \%$, $\mathrm{t}$-value $=-7.74)$ alongside increased posting volume $(+294.38 \%$, t-value $=10.31)$ and trading volume $(+925.65 \%$, t-value $=9.80)$ almost immediately following the publication of GCRs dossier.

Table 1 presents the daily values of the abnormal return, abnormal volume, posting volume and message board sentiment variables across the 31-day observation period. Table 2 provides values for the same variables, measured at five-minute periods during a 90-minute window surrounding the publication of GCRs tweet on day $d$. The data summarised in Table 1 highlight a significant change in abnormal community sentiment on day $d$, from a "bullish" 0.40 to a "bearish" -0.27 value, after which point the community continued to maintain a negative attitude towards Quindell PLC, until $d+8$ (abnormal daily sentiment between $d$ and $d+8=-0.12$ ). Before the publication of the GCR dossier the community sentiment for Quindell PLC was consistently positive (abnormal daily sentiment between $d-10$ and $d-1=0.16$, t-value $=4.53)$. 
Significant changes do not appear simultaneously across all four variables on the date of any other company announcements, or news coverage. This finding supports the argument that investors are liable to exhibit a stronger reaction to "high strength, low weight" news (since all the information contained in the GCR dossier was publicly available, and the language used in its report highly emotive) than news that is high in information content, but low in emotional strength (Griffin and Tversky, 1992; Barberis et al., 1998). The subsequent share purchase programme conducted by directors of Quindell PLC from $d+4$ to $d+7$ (noted in Table 1 ) had a varied effect on investor confidence; there was a statistically significant negative abnormal return $(-18.37 \%$ on $d+4$, t-value $=-3.60)$ followed the next day by a significant positive return $(+17.27 \%$, t-value $=3.29)$, which is then itself followed by relatively muted abnormal returns.

The online community sentiment value of -0.24 on the first day of the director share purchase programme suggests that these purchases did not achieve their aim of restoring investor confidence. Indeed, "bullish” company announcements after the GCR report coincide with relatively small - sometimes negative - abnormal returns, suggesting again that the arguably “high strength, low weight” content of GCR's dossier had a further, long-lasting effect on investor trust in Quindell PLC and its board. The intraday data summarised in Table 2 suggests a neutral "hold" opinion on behalf of the community (an average sentiment of zero is observed), until 1:00pm, when an initial spike in community sentiment arises, followed by negative sentiment (-0.52) for the one-hour period from 1:05pm. The first mention of the GCR note within the $A D V F N$ community occurs three minutes after the publication of GCR's tweet, indicating that community sentiment changed almost instantaneously despite the length of and detail in the GCR dossier. The escalation of (both online and offline) panic indicated by such radical shifts in sentiment and abnormal returns, suggests that social contagion was indeed 
present almost immediately following the publication of GCR's tweet and that a herd formed within the crowd. ${ }^{32,33}$

The statistically significant and almost instantaneous shift from bullish to bearish online user sentiment could be explained by a number of phenomena. For example, an event such as GCR's research note and the following share price reaction may be an example of the "attention bias” proposed by Barber and Odean (2008). ${ }^{34}$ Investors were made aware of the company through its substantial and rapid decline as well as abnormally high trade volume levels and visited the $A D V F N$ boards for information gathering purposes. Investors holding shares in the company may have felt a need to affirm their beliefs within online communities (Chen et al., 2008; Gilovich, 1991), especially following a situation where the financial community reacted overwhelmingly to a research report expressing sentiments that may have conflicted with their own. Message boards have been shown to facilitate confirmatory bias (Das et al., 2003) and where individuals join groups of like-minded types, they are especially prone to more extreme positions (Sunstein, 2009, p2). We would therefore expect to see increased sentiment levels in such a situation.

An influx of new users expressing negative opinion towards Quindell PLC may also have impacted our sentiment indicators. This view is supported by the extraordinary posting volume observed on day $d$. However, an analysis of the posters' usernames reveals that "new users” (that is, users who had not previously posted in Quindell PLC-specific threads throughout the observation window until day $d$ ) only accounted for $7 \%$ of posting volume on

\footnotetext{
${ }^{32}$ One message board participant, 'wolster', clearly articulated their confusion amidst the panic thus: "Surely there must be more to it than this single article? Surely some news has leaked out somewhere? I can't believe that one article from a suspect site would cause such a dramatic drop?”

${ }^{33}$ However, the authors acknowledge that the presence of both social contagion and information leakage (see Appendix 1) may be two of several possible reasons for the rapid price decline in shares of Quindell PLC, and further analysis of this would form an interesting extension of these findings.

${ }^{34}$ Whilst attention is put forward here as a potential bias, it should be acknowledged that there may be alternative explanations for the share price reaction to GCR's research note. Further analysis of this type would provide a useful extension to the present study.
} 
day $d$. Some $93 \%$ of messages on and after day $d$ were posted by users who had previously posted comments about Quindell PLC on ADVFN. It is therefore apparent that a number of existing active message board posters changed their beliefs following the publication of GCR's tweet; the findings thus point to a degree of social contagion and subsequent herding behaviour within the online community. ${ }^{35}$

Table 1 highlights a significant increase in activity across all variables between day $d$ and $d+5$, especially with regards to posting volume (significantly higher posting activity is observed each day from day $d$ to day $d+5$ ) suggesting that the GCR dossier continued to stimulate discussion long after its publication. Interestingly, the highest level of "buy" sentiment occurs on the day preceding the publication of GCR's tweet (abnormal sentiment = 0.40 on $d-1$, t-value $=3.57$ ) and immediately before the dissemination of GCR's research note to the ADVFN community (abnormal sentiment $=1.00$ at $1: 00 \mathrm{pm}$ on day $d$, t-value $=2.12$ ). This pattern is suggestive of "pump and dump" operations within the message board community, although it is difficult to arrive at a definitive conclusion about this point without knowing posters' intentions.

The next stage of the analysis investigates the relationship between abnormal returns and changes in sentiment (see Table 3) in order to assess causality; i.e. is sentiment driving market returns, or is community sentiment a product of preceding share price returns? The change in abnormal sentiment in Panel A is measured from one five-minute window to the next, and its association with different measures of activity is examined, but relatively few significant relationships are evident. We do however record a significant correlation of 0.15 between five-minute sentiment and posting levels over a three-day observation window,

\footnotetext{
${ }^{35}$ Evidence of increased posting activity also suggests a need to converse with and find comfort in the support of others holding similar beliefs. It may be the case that, in situations of extreme sentiment changes and "shock news", investors feel an increased need to justify their existing beliefs, and are directed to message boards for a level of reassurance.
} 
suggesting that a relationship, albeit one that is relatively small, exists between the two variables. ${ }^{36}$ Therefore, online community sentiment does appear to be associated with views of the wider investment community as measured by share returns. However, we find no convincing evidence that sentiment drives returns, or that returns cause sentiment changes, over 2-hour, 3-hour, 1-day and 2-day periods.

When the change in abnormal sentiment is lagged by 5 minutes however, a strong negative correlation with abnormal returns is identified in the 30 minutes (coefficient $=-0.90$ ), 45 minutes (-0.76) and 1 hour (-0.64) following publication of GCR's tweet. Therefore, over very short time periods, negative abnormal returns are followed by positive changes in community sentiment, and vice-versa, with the effect weakening as the time period lengthens. This is an unusual finding that is not documented in previous studies on the topic. More investigation of this association is therefore required since conclusions are difficult to draw given the small number of five-minute intervals considered in the shorter time periods examined.

Panel B presents analysis of the correlation between abnormal return and changes in sentiment measures over longer time horizons. Using the daily dataset, we find a much stronger positive correlation between changes in sentiment and abnormal returns over the 31-day observation window (0.55), suggesting that community sentiment and price returns operate in tandem. We further document that returns and sentiment are positively linked both before and after the release of GCR's dossier. Interestingly, the results indicate that this correlation increases in the trading days following day $d$ (coefficient $=0.66$ ) relative to the association beforehand (0.58). However, we again find no evidence of causality when introducing a lagged effect.

\footnotetext{
${ }^{36}$ We also conduct correlation analysis using our Bullishness Index and Modified Bullishness Index measures, and find similar results to those reported in Table 3 .
} 
In contrast to existing studies, such as the message-board investigation of Antweiler and Frank (2004) and the more recent study of public moods on Twitter by Bollen et al. (2011), we do not uncover any "predictive power" within online community postings and abnormal returns. We do, however, identify significant negative changes in community sentiment which coincide with negative abnormal returns immediately following the publication of GCR's tweet. Ultimately, therefore, it appears that the GCR dossier had an impact; its contents were rapidly disseminated among the online community, as uncertainty spread throughout internetbased posters, initiating a herd-like response. However, although our findings do not dismiss the notion that message board conversations are purely "noise", our observational evidence suggests that informational content is present. ${ }^{37}$

\section{CONCLUSIONS AND DISCUSSION}

Quindell PLC, a secondary-tier UK listed company, became the subject of a strongly critical research note disseminated via an online social media platform by secretive internet-based short seller Gotham City Research LLC (GCR) on $22^{\text {nd }}$ April 2014. The note valued Quindell PLC's shares much lower than its trading price at the time and, amongst other accusations, referred to Quindell PLC as a “Country Club Built on Quicksand” (Gotham City Research, 2014a). Despite GCR's contention that the company potentially “stood to profit in the event of the issuer's stock declining” (Gotham City Research, 2014a), the share price reacted almost

\footnotetext{
${ }^{37}$ News articles such as those of Morgenson (2002) provide anecdotal evidence of occasions in which information posted on stock message boards has proven to be more accurate than a majority of professional analysts' predictions. We identify a small number of messages identifying "red flags" in trading behaviour prior to the release of GCR's dossier by community participants. We earlier reported a discovery by Virgo (2014) of two large trades placed less than an hour before GCR's tweet. Table 2 shows an increase in posting volume from 12:30pm onwards. This is due, in part, to user interest in the two large orders. We identify at least one message board participant that acts upon this information by selling their holding before the publication of the tweet linking to GCR's dossier. Thus, this suggests that interactions within online communities cannot be considered as mere noise (Wysocki, 1998); informational content does appear to exist within the online community platform.
} 
instantly following a tweet linking to the 74-page dossier. This market reaction was cited by media outlets as one driven by panic (Ficenec and Martin, 2014); our evidence indicates that the release of GCR's report did indeed instigate a herding tendency within the crowd, with the high strength of GCR's negative report (Griffin and Tversky, 1992; Barberis et al., 1998) spreading rapidly following its online dissemination.

We find significant abnormal returns immediately following GCR's tweet coinciding with a significant change in sentiment from "bullish" to "bearish" among the online crowd. This negative sentiment persists long after the publication of GCR's dossier, whilst abnormal returns and community sentiment in the days following the publication of GCR's negative research note indicate that the trust between company directors and shareholders had been weakened. We conclude that the GCR dossier exploited a lack of transparency with regards to Quindell PLC's operations and thus instigated a rapid change in investor sentiment towards the company that ultimately caused the price of Quindell PLC shares to fall. However, there is no significant evidence to support the theory that abnormal returns following the publication of GCR's tweet were driven by the sentiment levels expressed online.

Whether the behaviour displayed by the online community can be classed as rational or "herd-like” is open to interpretation. The negative change in investor sentiment taking place within minutes of the release of GCR's dossier is surprising, given the length of the dossier in its entirety, and the time it would take for a rational agent to subsequently filter any informational content from noise. Further, as the content of GCR's dossier was already publicly available, we must query why this information was not already incorporated into the share price of Quindell PLC. The rise in both trading and posting volume shortly after the release of GCR's tweet could perhaps be explained by the rational act of information gathering, and/or the behavioural confirmation and attention biases. The significant and almost instant shift in 
sentiment may be the result, to some extent, of information overload, leading to non-optimal decision making and herding (Allen and Wilson, 2003).

Regardless, the events described in this study evidence an ever-increasing challenge for financial regulators. ${ }^{38}$ While we cannot discern the level of accuracy in GCR's claims regarding Quindell PLC, if the intent was “misrepresentation” and “manipulation”, as Quindell PLC (2014a) claimed, then the speed of dissemination and subsequent incorporation into community sentiment and share price could result in the damage having effectively already been done to a target company before regulators are able to act. This is a growing concern given the increasing popularity of social media platforms. ${ }^{39}$

\footnotetext{
${ }^{38}$ The number of market manipulation enforcements by the U.S. Securities and Exchange Commission, for example (which includes instances of pump-and-dump, and microcap securities fraud) increased to 63 in 2014, from 50, 46 and 35 in the preceding three years (U.S. Securities and Exchange Commission, 2015). A similar upward trend in online pump-and-dump related charges is evident from the SEC website, with 10 in 2015, and 11 in 2014, compared to 6 in 2013 and just 3 in 2012.

${ }^{39}$ From a contrary viewpoint, an announcement in August 2015 stating that Quindell PLC had become the subject of a criminal investigation by the Serious Fraud Office, leads to questions as to the effectiveness of current regulatory procedures governing secondary-tier markets, and the role of the nominated advisor ("nomad") in secondary-tier markets (Martinez, 2015). This may be perceived as justification of GCR's (2014b) claim that its motivation for the exposure of Quindell PLC was one of moral imperative. As a subsequent article within the Financial Times remarks, "anyone contemplating committing financial fraud at a listed company must now be fearful, in case the caped crusaders of the financial markets may swing in their direction” (Johnson, 2015).
} 


\section{REFERENCES}

Activist Insight. 2016. Active Investing: An Annual Review of Trends in Shareholder Activism.

http://www.activistinsight.com/amp/issues/The\%20Activist\%20Investing\%20Annual\%20Re view\%202016._260.pdf

Activist Shorts Research. 2014. Activist Shorts 2014: Year in Review. https://www.activistshorts.com/documents/Activist\%20Shorts\%202014\%20Year\%20in\%20R eview.pdf

Adjei, F., Cyree, K.B., Walker, M.M. 2008. "The determinants and survival of reverse mergers vs IPOs." Journal of Economics and Finance 32 (2): 176-194

Allen, D. \& Wilson, T. D. 2003. “Information Overload: Context and Causes”. New Review of Information Behaviour Research 4 (1): 31-44

Antweiler, W., Frank, M.Z. 2004. "Is all that talk just noise? The information content of internet stock message boards”. Journal of Finance 59 (3): 1259-1294

Avery, C., Zemsky, P. 1998. "Multidimensional Uncertainty and Herd Behaviour in Financial Markets”. American Economic Review 88 (4): 724-748

Baker, W.E. 1984. "The Social Structure of a National Securities Market”. The American Journal of Sociology, 89 (4): 775-811

Barber, B.M, Odean, T. 2001. “The Internet and the Investor”. Journal of Economic Perspectives 15 (1): 41-54

Barber, B.M., Odean, T. 2008. "All That Glitters: The Effect of Attention and News on the Buying Behavior of Individual and Institutional Investors”. Review of Financial Studies 21 (2): $785-818$

Barberis, N., Shleifer, A., Vishny, R. 1998. “A Model of Investor Sentiment”. Journal of Financial Economics 49 (3): 307-343

Bases, D., Vlastelica, R., Baldwin, C., Bendeich, M. 2011. "Special report: The shorts who popped a China bubble”. Reuters, August 5. http://uk.reuters.com/article/2011/08/05/uschina-accounting-shorts-idUSTRE7740PC20110805

Becht, M., Franks, J., Mayer, C., Rossi, S. 2010. "Returns to shareholder activism: Evidence from a clinical study of the Hermes UK Focus Fund." Review of Financial Studies 23 (3): 3093-3129.

Bentley, R.A., O'Brien, M.J., Brock, W.A. 2014. "Mapping Collective Behavior in the BigData Era." Behavioral and Brain Sciences 37 (1): 63-76

Bikhchandani, S., Hirshleifer, D., Welch, I. 1992. “A Theory of Fads, Fashion, Custom, and Cultural Change as Informational Cascades”. Journal of Political Economy 100 (5): 9921026 
Bollen, J., Mao, H., Zeng, X. 2011. "Twitter mood predicts the stock market”. Journal of Computational Science 2 (1): 1-8

Bruner, R.F. 1999. “An Analysis of Value Destruction and Recovery in the Alliance and Proposed Merger of Volvo and Renault”. Journal of Financial Economics 51 (1999): 125166

Campbell, P. 2014. “All Eyes Fixed on Secretive 'Country Club': How Rollercoaster Quindell Became a Darling and Demon to Investors”. This Is Money, July 2. http://www.thisismoney.co.uk/money/markets/article-2676788/CITY-FOCUS-Quindelldarling-demon-investors.html

Cannacord Genuity Group Inc. 2013. “Company Initiation of Coverage UK: Quindell Portfolio". http://dcms.canaccordgenuity.com/ResearchNotes/887d841c06d248c68d1b3d96d6074dd9.pd $\mathrm{f}$

Castellain Capital. 2016. Short Interest Tracker - Fund Managers. 5 October 2016. http://shorttracker.co.uk/manager

Chambers, C. 2006. “Using Financial Message Boards”. Technical Analysis of Stocks and Commodities 24 (4) : 47-50

Chen, H.S.M., Gu, B., and Konana, P. 2008. "Melting-Pot or Homophily? - An Empirical Investigation of User Interactions in Virtual Investment-Related Communities”. Working Paper. University of Texas

Chen, H.S.M., 2013. Group polarization in virtual communities: The case of stock message boards. In iConference 2013 Proceedings, 185-195

Chen, H.S.M., Prabuddha, D., Hu, Y., Byoung-Hyoun, H. 2013. "Wisdom of Crowds: The Value of Stock Opinions Transmitted Through Social Media”. Review of Financial Studies 27 (5): 1367-1403

Chen, L. 2015. The informational role of internet-based short-sellers. Working Paper. Southwestern University of Finance and Economics

Chung, J. 2014. “Gotham City Research Unmasks Gowex but Stays in Shadows”. The Wall Street Journal, July 9. http://www.wsj.com/articles/gotham-city-research-works-in-theshadows-1404842379

Collingridge, J., Fortson, D. 2014. “Quindell’s house of cards?” The Sunday Times, April 27. http://www.thesundaytimes.co.uk/sto/business/Finance/article1404024.ece

Cook, D.O., Xing, L., Zhang, Y., Zhou, T. 2014. The Asymmetric Stock Message Board Effect. Working Paper. University of Alabama.

Das, S., Martinez-Jerez, A., Tufano, P. 2003. E-Information: A Clinical Discussion of Investor Discussion and Sentiment. Working Paper. Harvard Business School

Das., S.R., Chen. M.Y., 2007. "Yahoo! For Amazon: Sentiment Extraction from Small Talk on the Web”. Management Science 53 (9): 1375-1388 
Das, S., Martinez-Jerez, A., Tufano. P. 2005. "eInformation: A Clinical Study of Investor Discussion and Sentiment." Financial Management 34 (3): 103-137

Devenow, A., Welch, I. 1996. "Rational Herding in Financial Economics”. European Economic Review 40 (3): 603-615.

Dewally, M. 2003. "Internet Investment Advice: Investing With a Rock of Salt”. Financial Analysts Journal 59 (4): 65-77

Fan, M., Stallaert, J., Whinston, A.B., 2000. “The Internet and the future of financial markets”. Communications of the ACM 43 (11): 82-88

Ficenic, J., Martin, B. 2014. “The Day Gotham City’s Tweet Cost Quindell £1bn”. The Telegraph, April 26.

http://www.telegraph.co.uk/finance/newsbysector/banksandfinance/insurance/10790021/Theday-Gotham-Citys-tweet-cost-Quindell-1bn.html

Foust, D., 2001. “Caveat Poster”. Yahoo! Internet Life Magazine. November 2001 (120)

Frazer, S. 2013a. “Quindell Wins War with Sceptics”. Shares Magazine, December 18. http://www.sharesmagazine.co.uk/news/quindell-wins-war-with-sceptics\#.VZBupflVikp

Frazer, S. 2013b. “Quindell eyes FTSE 100”. Shares Magazine, March 13. http://www.sharesmagazine.co.uk/news/quindell-eyes-ftse-100\#.VZBO3vlVikp

Gilovich, T. (1991) How We Know What Isn't So: The Fallibility of Human Reasons in Everyday Life. New York: Free Press

Gordon, O. 2014a. “Gotham City Gets Its Man”. City A.M. 2259 (1), November 18

Gordon, O. 2014b. "Rob Terry Departs Quindell: How Gotham City Got its Man”. City A.M., November 18. http://www.cityam.com/1416277858/gotham-city-gets-its-man

Gotham City Research. 2014a. A Country Club Built on Quicksand.

http:/gothamcityresearch.com/2014/04/22/quindell-plc-a-country-club-built-on-quicksand/

Gotham City Research. 2014b. Gotham City Research's Formal Response to Gowex \& Jenaro Garcia Martin's Public Confession.

https://www.unience.com/file/download/blog/003a2cdbdab014711f199a7a2cdbdab014711f1 99a7

Griffin, D., Tversky, A. 1992. "The Weighing of Evidence and the Determinants of Confidence”. Cognitive Psychology 24 (3): 411-435

Gu, B., Konana, P., Chen, H.S.M. 2008. "Melting-Pot or Homophily?-An Empirical Investigation of User Interactions in Virtual Investment-Related Communities". McCombs Research Paper Series, May 2008

Holderness, C.G., and Sheehan, D.P. 1985. "Raiders or Saviours? The Evidence on Six Controversial Investors." Journal of Financial Economics, 14 (4): 555-579

Investegate. 2016. Company Announcements by Sector. http://www.investegate.co.uk/Index.aspx?sType=sector\&date=20161108\&sector=TECH\&se $\operatorname{archFlag}=1$ 
Johnson, M. 2014. “Tiger Global used shell company to short sell Quindell”. The Financial Times, November 20. https://www.ft.com/content/a458f5da-70a4-11e4-9129-00144feabdc0

Johnson, M. 2015. "Short selling's new sultans take the stage”. The Financial Times, March 16. http://www.ft.com/cms/s/0/46f0cb26-b6d5-11e4-95dc-

00144feab7de.html\#axzz3m1ghH9ws

Jones, Q., Gilad, R., Sheizaf, R. 2004. “Information overload and the message dynamics of online interaction spaces: A theoretical model and empirical exploration”. Information Systems Research 15 (2): 194-210

Kelley, T. 2014. “Gotham’s Batman of Short-sellers Takes Down Spain’s Gowex”. Bloomberg Business, July 7. http://www.bloomberg.com/news/articles/2014-07-07/shortseller-yu-channels-batman-in-takedown-of-gowex

Leinweber, D.J., Madhavan, A.N. 2001. "Three hundred years of stock market manipulations”. The Journal of Investing, 10 (2): 7-16

Liu, H., Xu, N., \& Ye, J. 2015. “Short sellers' accusations against Chinese reverse mergers: Information analytics or guilt by association?” China Journal of Accounting Research 8 (2): 111-131.

Mackay, C. (1841) 2004. Extraordinary Popular Delusions and the Madness of Crowds. Reprint, USA: Barnes \& Noble Publishing

Mance, H. 2014a. “Quindell’s troubles put founder Rob Terry's past in spotlight”. The Financial Times, November 17. http://www.ft.com/cms/s/0/62565424-6da3-11e4-bf8000144feabdc0.html\#slide0

Mance, H. 2014b. “Quindell hit by further doubts”. The Financial Times, April 25. http://www.ft.com/cms/s/0/1d5b32b2-cca0-11e3-9b5f-00144feabdc0.html\#axzz3XTwMsEbk Mance, H. 2014c. “Who is Gotham City Research?” The Financial Times, April 23. http://www.ft.com/cms/s/0/a841ea38-ca4d-11e3-8a31-00144feabdc0.html\#axzz3XwyQiiKT

Mance, H., Thomas, D., Burgess, K. 2014. “Quindell Rejected for Main Market Listing”. The Financial Times, June 11. http://www.ft.com/cms/s/0/26744cec-f155-11e3-916100144feabdc0.html\#axzz3YhjGVy3u

Marlow, B., Dennys, H. 2014. “Gotham City Research: Who is Daniel Yu?” The Telegraph, July 12.

http://www.telegraph.co.uk/finance/newsbysector/banksandfinance/10963645/Gotham-CityResearch-who-is-Daniel-Yu.html

Martinez, A.G. 2015. “Alternative Investment Markets under Criticism: Reasons to be Worried? Lessons from Gowex”. Journal of Financial Regulation, Advance Online Publication

McPherson, M., Smith-Lovin, L., Cook., J.M. 2001. "Birds of a Feather: Homophily in Social Networks." Annual Review of Sociology 27: 415-444 
Mendoza, J.M. 2008. "Securities Regulation in Low-Tier Listing Venues: The Rise of the Alternative Investment Market”. Fordham Journal of Corporate and Financial Law 13 (2), 257-328

Mendoza, M., Poblete, B., Castillo, C. 2010. "Twitter Under Crisis: Can We Trust What We RT?" In Proceedings of the first workshop on social media analytics, ACM, 71-79, 2010

Morgenson, G. 2002. "The Bears on this Message Board had Enron Pegged”. The New York Times, 28 April. http://www.nytimes.com/2002/04/28/business/yourmoney/28WATC.html

Morris, M.R., Counts, S., Roseway, A., Hoff, A., Schwarz, J. 2012. “Tweeting is Believing? Understanding Microblog Credibility Perceptions”. Proceedings of CSCW, 2012

Nardo, M., Petracco-Giudici, M., Naltsidis, M. 2015. "Walking Down Wall Street With a Tablet: A Survey of Stock Market Predictions Using the Web”. Journal of Economic Surveys, Advance Online Publication

Perromat, P; Michel, J. 2014. “Gowex Conquerer Gotham City Shrouded in Mystery”, Yahoo! News. July 16. http://news.yahoo.com/gowex-conquerer-gotham-city-shroudedmystery-042300040.html

Quindell PLC. 2014a. “Response to Speculation”. Quindell Investor Relations, 22 April 2014. http://www.quindell.com/press-releases-rns/response-to-speculation

Quindell PLC. 2014b. "Detailed Response to Gotham City Speculation”. Quindell Investor Relations, 25 April 2014. http://www.quindell.com/Press-Release/detailed-response-togotham-city-research-speculation

Quindell PLC. 2015a. “Proposed Sale of the Professional Services Division”. Quindell Investor Relations, March 30. http://www.quindell.com/press-releases-rns/proposed-sale-ofthe-professional-services-division

Quindell PLC. 2015b. “Quindell PLC: About Us”. Quindell Investor Relations. http://www.quindell.com/about/about-quindell-plc

Resnick, P., Kuwabara, K., Zeckhauser, R., Friedman, E., 2000. "Reputation Systems”. Communications of the ACM 43 (12): 45-48

Russ, C. 2007. “Online Crowds - Extraordinary Mass Behavior on the Internet”. Proceedings of I-MEDIA '07 and I-SEMANTICS ’07, 2007

Ryan, J. 2006. Examining Market Reaction to Activist Investor Campaigns by Hedge Funds. Working Paper.

Schumaker, R.P., Chen. H. 2009. "A Quantitative Stock Prediction System Based on Financial News." Information Processing \& Management 45 (5): 571-583

Shefrin, H. 2000. Beyond Greed and Fear: Understanding Behavioural Finance and the Psychology of Investing. Boston: Harvard Business School Press

Shiller, R.J. 1984. “Stock Prices and Social Dynamics”. Brookings Papers on Economic Activity, 2: 457-510 
Simonsohn, U., Ariely, D. 2008. "When Rational Sellers Face Non-Rational Buyers: Evidence from Herding on eBay”. Management Science 54 (9): 1624-1637

Statman, M. 1999. "Behavioral Finance: Past Battles and Future Engagements”. Financial Analysts Journal 55 (6): 18-27

Steiner, P. 1993. “On the Internet, Nobody Knows You're a Dog”. The New Yorker 69 (20): 61

Sunstein, C.R. 2009. Going to Extremes: How Like Minds Unite and Divide. New York: Oxford University Press.

Thornton, D., 2015. “It’s Been Another Rollercoaster Week for Quindell”. The Daily Reckoning UK, April 2. http://www.dailyreckoning.co.uk/penny-shares/its-been-anotherrollarcoaster-week-for-quindell/

Tumarkin, R., Whitelaw, R. 2001. "New or Noise? Internet Postings and Stock Prices”. Financial Analysts Journal 57 (3): 41-51

U.S. Securities and Exchange Commission. 2015. Year-by-Year SEC Enforcement Statistics. https://www.sec.gov/news/newsroom/images/enfstats.pdf

Vermeulen, E. 2015. "High-Tech Companies and the Decision to Go Public: Are Backdoor Listings Still an Alternative to Front-Door Initial Public Offerings." Penn State Journal of Law \& International Affairs 4 (1): 421-444

Virgo, J. 2014. “Who's the Joker? Gotham City Attacks UK Firm”. Ancoa Software Ltd, May 2. http://ancoa.com/who-is-the-joker/

Williams, M. 2015. "Scots Stockmarket Trader 'Faked Twitter Accounts in £1m US Stock Fraud”". Herald Scotland, November 6.

http://www.heraldscotland.com/news/13949403.Scots_stockmarket_trader_faked_Twitter_a ccounts_in__1m_US_stock_fraud_/

Williams-Grut, O. 2015. "Scandal-hit Quindell Sells Legal Arm to Slater \& Gordon for £637m”. The Independent, March 31.

http://www.independent.co.uk/news/business/news/scandalhit-quindell-sells-legal-arm-toslatergordon-for-637m-10145122.html

Wysocki, P. 1998. Cheap Talk on the Web: The Determinants of Postings on Stock Message Boards. Working Paper. University of Michigan Business School.

Zhang, Y. 2014. Stock Message Boards: A Quantitative Approach to Measuring Investor Sentiment. New York: Palgrave Macmillan

Zhang, Y., Nguyen, G.X., Le, S.V. 2010. "Yes, Value Line Enigma Is Still Alive: Evidence from Online Timeliness Rank Changes”. The Financial Review 45 (2): 355-373 


\section{APPENDIX 1}

\section{BACKGROUND: QUINDELL PLC AND GOTHAM CITY RESEARCH}

On $30^{\text {th }}$ March 2015, following a "very difficult” 12-month period with “a lot of turbulence” (Williams-Grut, 2015), Quindell PLC announced a "break from the past”, in which eight existing members of the board would step down from their respective positions and the Professional Services Division, representing approximately $75 \%$ of the business, would be acquired by Australian legal firm Slater and Gordon (Quindell PLC, 2015a). The announcement provided a significant contrast to the ambitions of the company some 12 months previously, when Quindell PLC was considered by many within the media and online bulletin boards to be “on the brink" of promotion to FTSE 250 status $^{40}$ (Frazer, 2013b).

Upon purchase of a golf and country club in Hampshire in 2003, Mr Terry rebranded the business as “Quindell” (Mance, 2014a). Company Annual Reports through until 2007 described the principal activity of Quindell Ltd as a company operating in the leisure industry. According to the Internet Archive, the 2008 Annual Report, followed by an updated website in late 2009, were the first references by the company to its 'Telecoms', 'Business Solutions' and ‘Technology Solutions’ operations. Quindell PLC gained entry to the Alternative Investments Market following a reverse acquisition of Mission Capital PLC in May 2011 (Quindell PLC, 2015b), a corporate action that “barely registered on the City radar” (Campbell, 2014).

Nonetheless, the company instigated an aggressive acquisition-fuelled growth strategy (Thornton, 2015), acquiring approximately 30 companies operating within the legal and technology industries for a combined total of $£ 250$ million over a period of three years (Mance, 2014b). This rapid growth attracted the attention of the investment community. One news

\footnotetext{
${ }^{40}$ In an interview during 2013, the former-CEO Mr Terry exuberantly exclaimed, “This business is going to be a FTSE 100 [company]” (Collingridge and Fortson, 2014).
} 
source in 2013 reported that Quindell had "won over many of its past sceptics", with institutional investors such as Prudential having substantial equity stakes in the firm (Frazer, 2013a).

However, a number of sceptics remained; some analysts shied away from valuing the firm due to the lack of transparency rendering an accurate valuation difficult to derive (Campbell, 2014). Indeed, in 2013 Quindell PLC’s own broker at the time, Canaccord Genuity (2013, p. 6), published a research note suggesting the company has "not necessarily made it easy to grasp how it generates revenues and profits”. Despite this, a 'buy' recommendation was awarded to Quindell PLC's shares, with the argument that the firm's continually low P/E ratio may have been due to misplaced concern regarding the business model ${ }^{41}$. On the date prior to GCRs dossier publication, Quindell PLC shares closed at 585p per share ${ }^{42}$, an increase of 550\% on the previous year's lowest close of 90p, suggesting strong levels of investor confidence about the company's future growth prospects.

The 74-page dossier “Quindell PLC: A Country Club Built on Quicksand” was published online by GCR on 21 ${ }^{\text {st }}$ April 2014 (Gotham City Research, 2014a). Curiously, the market appeared not to respond to this information initially. Instead, the price of Quindell PLC shares on the Alternative Investments Market only dropped by a sizeable amount shortly after 1.00pm on $22^{\text {nd }}$ April 2014, around the time of a 'tweet' on the microblogging site 'Twitter', at 1.02pm, from the username ‘@GothamResearch’ which linked to the dossier. Three months prior to the tweet, archived web data shows that there were approximately 2,300 followers of the account '@Gotham Research'. Within 40 minutes of the initial tweet, the share price of Quindell PLC had fallen by 52.6 percent (Ficenec and Martin, 2014).

\footnotetext{
41 "If [Quindell] has hoodwinked the investment community, it has also managed to pull the wool over the eyes of virtually every top ten UK insurer and their auditors" (Cannacord Genuity, 2013, p1) 
GCR’s research note aggressively attacked Quindell PLC’s business and accounting practices, concluding:

- Approximately 80 percent of Quindell PLCs Earnings Before Interest, Tax, Depreciation and Amortisation (EBITDA) for the financial year (FY) 2012 and 43 percent of EBITDA for FY 2013 could not be reconciled or explained (Gotham City Research, 2014a, p6);

- Quindell PLC’s largest customer during FY 2009 and FY 2010 was itself, through dealings with a subsidiary company (Gotham City Research, 2014a, p17);

- A number of entities acquired by Quindell PLC were argued to be "phantom” companies, lacking economic substance and resembling “little more than paper companies” (Gotham City Research, 2014a, p30);

- The company possessed no free cash and had a negative operating cash flow (Gotham City Research, 2014a, p3);

- The existence of Quindell PLC's office in New York and other international offices was called into question (Gotham City Research, 2014a, p3).

Furthermore, GCR published a disclaimer within their dossier suggesting that they may have held a short position in Quindell shares prior to publication of the research:

"You should assume that as of publication of this report, GOTHAM CITY RESEARCH LLC stands to profit in the event the issuer's stock declines.” (Gotham City Research, 2014a, p2).

Quindell PLC’s immediate response to GCR's dossier, published some hours later, dismissed the assertions made as "highly defamatory and deliberately misrepresentative", adding that “[Quindell] is reporting coordinated shorting activity to the appropriate authorities” (Quindell PLC, 2014a). A further comprehensive rebuttal to each accusation by GCR was published on the company website three days later (Quindell PLC, 2014b). However, by then a sizeable share 
price decline had occurred and those who had gone short in Quindell PLC’s shares had made large gains. The existence of short positions in Quindell PLC's shares was identified by James Virgo (2014) at Ancoa, a surveillance and analytics firm, in which two large trades are identified at $12.14 \mathrm{pm}$ and $12.15 \mathrm{pm}$, less than an hour prior to the release of GCRs tweet, linking to the GCR report ${ }^{43}$.

Despite increased scrutiny from the British media following the share price reaction to its report on Quindell PLC on 22nd April, GCR has maintained an "air of mystery” (Chung, 2014). The company lists no contact details on its website, does not sign reports, and does not identify any personnel (Perromat and Michel, 2014). Outside of the short-seller community, GCR was relatively unknown (Chung, 2014). The opaque nature of this organisation has raised questions about their motives and tactics; yet this feature of its operations is also perceived by some as enhancing the research firms "superhero image” (Marlow and Dennys, 2014).

A Financial Times article profiling GCR, published on the day following the Quindell PLC controversy, links the research organisation to a trader located in New York - Daniel Yu. The same article describes the company’s approach as “go short then go public” (Mance, 2014c). The months following the publication of GCR's report on Quindell PLC have seen a great deal of debate via online platforms, expressing polarised opinion towards short-selling firms, and their utilisation of online communities and social media as a tool to disseminate criticism of target companies. During an interview with media company Bloomberg, $\mathrm{Mr} \mathrm{Yu}$ described GCRs actions towards Quindell PLC, and other companies that the short-seller had 'exposed', in moral terms ${ }^{44}$. Furthermore, following GCR's exposure of Gowex SA, a Spanish

\footnotetext{
${ }^{43}$ Virgo (2014) notes the irregular size of the transactions, each with a value of over $£ 3.3$ million. 44 Comparing his actions to the fictional Gotham City superhero 'Batman', Mr Yu claimed: "[Batman] always worked within the spirit and the letter of the law. He's not a vigilante. He realises that the authorities have scarce resources and limited personnel. We are driven to show people that the world doesn't belong to seemingly untouchable wrongdoers....For a lot of these companies, the truth is their enemy” (Kelley, 2014)
} 
telecommunications provider that subsequently filed for bankruptcy and admitted reporting falsified financial results over a four year period, Yu justified the "critical role” of short-sellers within the financial markets and asserted that the response of regulators in the wake of such events should "not be to shoot the messenger" (Kelley, 2014).

Supporters of short-seller firms claim them to be necessary as a counterweight to bullish analysts and fraudulent behaviour within corporations. By contrast, critics propose that the claims of such short-seller firms are not always accurate, usually unsupported by evidence and concerned primarily with profit for themselves (and a favoured few) at the expense of most shareholders (Chung, 2014). The current paper examines these contrasting views of shortsellers who use the internet to criticise their investee companies. 